\title{
acción integral con menores ¿QUÉ HACE UN PROFESOR JUBILADO EN UN GALLINERO COMO ÉSTE?
}

http://dx.doi.org/I0.14422/pym.v0i356.3066

Paco Pascual

Profesor/orientador jubilado y voluntario forzoso

Antiguo alumno de Jesús Garrido SJ.

pacopascuall0@gmail.com

\section{I. ¿Qué es el Gallinero? Sus habitantes}

I Gallinero, el mayor asentamiento chabolista europeo de familias roma (que conocemos también como de etnia gitana) está situado en un solar que antiguamente era una granja avícola, de ahí su nombre. Noventa familias, más de 650 personas, la mitad de ellos niños, viven en unas condiciones más que precarias a tan sólo unos kilómetros de la Puerta del Sol, en el kilómetro 13 de la A-3 (Madrid-Valencia), cerca de la Cañada Real Galiana - aunque no forma parte de ella-y dentro del distrito de Villa de Vallecas.

Estas familias han emigrado de Jăndărei, localidad situada al sudeste de Rumanía; muchos de ellos, los más jóvenes, apenas han estado en el país. En la actualidad se identifican como una comunidad, dadas las redes de apoyo creadas entre las personas del poblado. El proceso migratorio propicia que se identifiquen, además de por pertenecer a una minoría étnica, con su país de origen y sobre todo por ser ciudadanos de Madrid, donde residen desde hace más de diez años.

El poblado lo forman tres calles donde se alinean noventa chabolas de madera, cartón y plástico, sin divisiones internas: una sala de estar dormitorio, de unos $15 \mathrm{~m}^{2}$, ocupada por camas, televisión y lugares donde colocar ropa y útiles. Las paredes están forradas con telas para intentar aislarse del frío. En un pequeño porche colocan la cocina y la lavadora. La vida, si hace buen tiempo, la hacen al aire libre.

No disponen de agua corriente, ni letrinas, ni duchas o lavabos. El agua la obtienen de una tubería cercana desde donde, normalmente los niños, la transportan con bidones. Cada chabola toma la luz eléctrica a través de un cableado que comunica con la torreta transformador. El sistema es muy inestable y peligroso: en los días de lluvia y nieve las averías son constantes y los cortocircuitos, al juntarse cables de fundas roídas por las ratas, provocan todos los inviernos dramáticos incendios de varias chabolas aunque hasta ahora no haya habido que lamentar víctimas.

Los voluntarios que trabajan en la zona, principalmente miembros de las parroquias de Santo Domingo de la Calzada y de San Carlos Borromeo, han conseguido, al cabo de ocho años, con el apoyo de la Cruz Roja y el IRIS (Instituto de Realojamiento e Integración Social), que todos de los niños de 3 a 16 años estén escolarizados. No han logrado, a pesar de los esfuerzos, lo que consideran el punto de arranque de toda educación: la escuela infantil para los niños de 0-3 años.

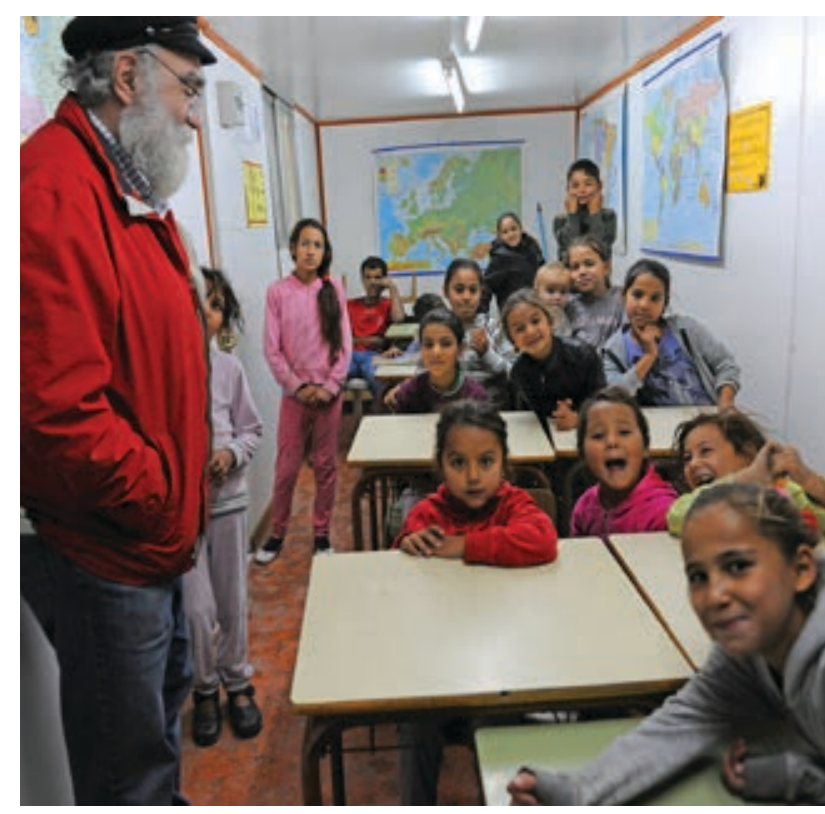

El autor, contando cuentos. 
II. UN PLANTEAMIENTO INTEGRAL COMUNITARIO QUE SITÚA EL FOCO EN EL MENOR DENTRO DE SU FAMILIA

Se trata de llevar a cabo un trabajo sociofamiliar con el niño y su familia. Un seguimiento familiar en el que planificar objetivos y acompañar a la familia en un itinerario de inserción individualizado, poniendo a su disposición los recursos necesarios para que pueda superar la situación en la que se encuentra.

Paralelamente a este trabajo de seguimiento familiar y con el telón de fondo del enfoque comunitario se plantea hacer:

- Una intervención comunitaria que aborde otros aspectos esenciales tales como la situación legal en cuanto a empadronamiento, pasaporte, etcétera.

- Una dinamización social del poblado en su conjunto, organizando la cobertura de las necesidades básicas tales como la mejora de las chabolas mediante la dotación de suelo y techo, la mejora en la seguridad de la instalación eléctrica, la colaboración en la adquisición de electrodomésticos (calefactor seguro, nevera, lavadora - ésta repercute directamente en la limpieza con la que los niños acuden a la escuela-), mejora del firme y limpieza de las calles, recogida de la basura, la gestión adecuada del agua, construcción de una zona infantil de juegos, campo fútbol, etcétera. En este sentido conviene destacar también la importancia de la relación con otros actores que intervienen en la vida del poblado (IRIS, educadores del Ayuntamiento, Cruz Roja, otros voluntarios...) con el fin de aprender de y con ellos, y hacer una intervención común que amplifique los recursos con los que contamos.

- Una mejora de las condiciones de salud de las familias en general, a través de talleres de salud para mujeres, educación sexual, primeros auxilios, hábitos higiénico sanitarios, etcétera.

La intervención se inicia en el año 2005 con el nacimiento del poblado y con un planteamiento integral comunitario que sitúa el foco en el menor dentro de su familia y sin dejar de atender la mejora de las condiciones de vida que van a ser determinantes en los procesos socioeducativos y todo ello en el marco de la defensa de sus derechos.

La meta última es la quiebra de la inercia que lleva a los niños de hoy a repetir la forma de vida de sus padres, en lo que de negativo tienen, reconociendo y potenciando sus valores.

Las prioridades son:

- Atender las necesidades educativas de la población en edad escolar por medio de la integración en las escuelas ordinarias.

- Combatir el absentismo y el abandono escolar.

- Lograr la progresiva alfabetización de la población adulta bajo los lemas: Níciodata este triciu pentru a invata, es decir, "Nunca es tarde para aprender", y Nu cere, invata, "No pidas, aprende".

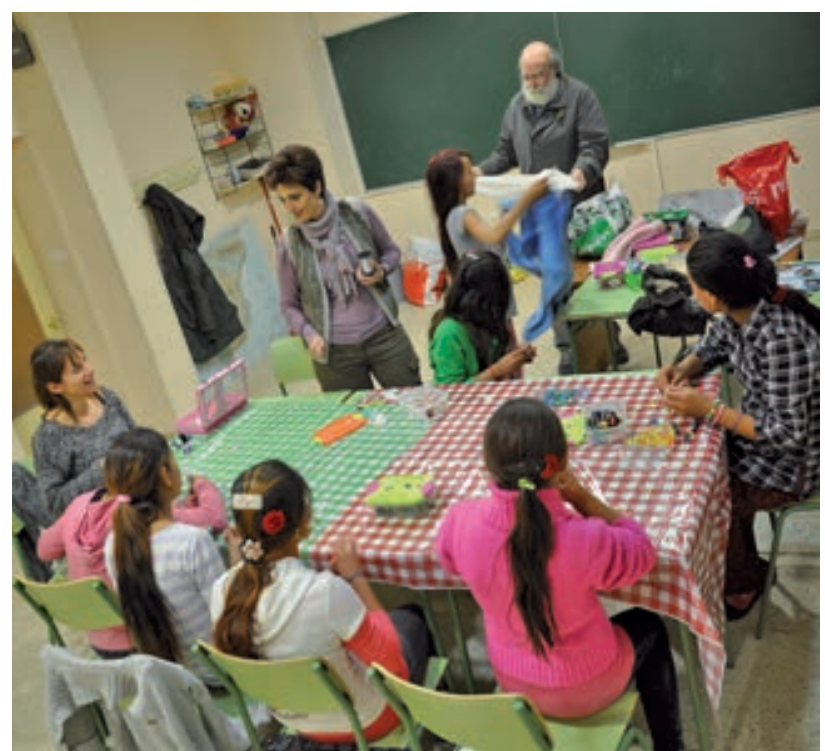

El trabajo y la educación, es decir, el aprendizaje de los conocimientos por los que la cultura se perpetúa, y su concreción más común en alguna forma de escuela, constituyen las dos principales actividades capaces de integrar socialmente y de promocionar a las personas para evitar la reproducción de la marginalización intergeneracional. Ambas son clave, se fortalecen y potencian mutuamente.

\section{Qué llevamos haciendo en este tiempo}

\section{LA eSCOLARIZACIÓN DE LOS NIÑOS}

En un principio, aunque hay excepciones, los padres presentan una inicial indiferencia hacia la escolarización de sus hijos; sin embargo una vez que están escolarizados esta actitud cambia, a veces radicalmente, demandando expresamente la escolarización.

Las familias encuentran beneficios tales como la comida del mediodía, y que sus hijos están protegidos y atendidos, quedando más libertad de movimientos para los padres. Por tanto, no podemos aceptar la expresión "los padres no muestran interés por la escolarización de sus hijos", como excusa para la inacción institucional. Asimismo los padres no son los únicos responsables, también lo son las administraciones. Cuando se afirma que las administraciones sólo están obligadas a ofertar el puesto escolar y si los niños no van al colegio es responsabilidad exclusiva de sus padres, se está ignorando la propia legislación que habla de "hacer una discriminación positiva para compensar desigualdades”.

\section{Trabajar contra el absentismo}

Podemos organizar en dos grupos las causas del absentismo entre los niños rumanos de El Gallinero.

a) Provienen de su entorno:

I. Las niñas, a partir de 10 años aproximadamente, cuidan a los hermanos pequeños, ausentándose de la escuela. Al tener la madre que salir de la casa para buscar el sustento, son las niñas mayores las que cuidan de los pequeños. 
2. La pronta llegada de los menores al estatus y rol de adulto, más evidente en el caso de las niñas que en torno a los 12 años se visten con la ropa tradicional (faldas largas y pañuelo a la cabeza).

3. La movilidad residencial de estas familias hace que se obstaculice el progreso en el aprendizaje.

4. Falta de ropa y calzado adecuada (por estas causas a veces se inhiben, avergonzados, de acudir al colegio). Son los pequeños los que objetan que no tienen bocadillos como sus compañeros. Sin embargo, son estos niños pequeños los que mejor se integran: cuanto antes es la incorporación a la escuela, mejor y más rápidamente se integran con sus compañeros y aprenden rápidamente el idioma.

5. Por enfermedad: bronquitis, constipados, gripes (a causa de las condiciones de humedad y frío de las chabolas e infraviviendas).

6. No me despertaron, perdí el autobús (no hay otro modo de ir que el bus escolar).

b) Provienen de la propia escuela:

I. Reciben continuos castigos: estos niños no tienen incorporadas "nuestras" reglas de comportamiento (tienen las suyas propias, diferentes y desajustadas a la institución escolar). Por ello, de entrada "no las cumplen" y son continuamente castigados.

2. Los gitano-rumanos son agredidos por otros niños gitanos españoles.

3. No hay relación entre la familia y el colegio.

4. Los colegios no tienen los suficientes apoyos para responder a las necesidades específicas de estos niños.

5. Son escolarizados en clases de niños de su misma edad, cuando no tienen los mínimos conocimientos y habilidades para ello. Carecen de apoyos compensatorios.

6. Conocen el idioma pero no se expresan adecuadamente en él, no saben leerlo ni escribirlo.

\section{Propuesta de actuaciones}

Hay muchas acciones para poner en marcha. La creación de un aula materno infantil de $\mathrm{I}$ a 3 años in situ es la primera de ellas. Cuanto antes empecemos a intervenir en la vida de los niños, más eficaz será su adquisición de un modelo de conducta adaptado que les posibilite la incorporación en la institución escolar y en nuestra sociedad en general. Un aula de apoyo escolar, con objetivos de refuerzo compensatorio y apoyo en la realización de las tareas escolares, imposible de realizar en sus chabolas.

Se impone mejorar el acceso al currículum, con acciones como construir una marquesina para la parada del autobús de ruta escolar, dando así cobijo y seguridad a los niños; despertarlos y proporcionar un bocadillo o bollo para el recreo; facilitar material escolar, ropa adecuada, etcétera.

Impulsar, mediante el trabajo de mediadores y educadores, la relación de la familia con la escuela y facilitar el acceso a actividades extraescolares (excursiones y salidas culturales) mediante subvenciones.

Poner en marcha la alfabetización de adultos. Una maestra, rumana para mejorar la comunicación en su idioma, va todas las tardes tres horas a trabajar con los adultos. Si hay sitio en la escuela, deja entrar a los niños que han perdido el bus escolar para que así no pasen el día sin escuela.

Atención educativa a los "mayores", es decir, niñas y niños de más de II años que no consiguen adaptarse a la escuela y son absentistas o han hecho abiertamente un abandono prematuro. Intervención centrada en contenidos de formación profesional y prelaboral.

No sirve argumentar que hasta los 16 años tienen que permanecer en las escuelas pues la ley así lo establece, cuando en la práctica no es así, ya que están ausentes, en la calle, y las instituciones no hacen nada para evitarlo. El resultado final es que los niños y adolescentes permanecen en la calle, sin trabajar por no tener la edad legal y nula o baja formación laboral. Así nacen el proyecto "NIDO" y el proyecto "MALALA".

\section{Proyectos}

PRoYecto “NIDO”

La parroquia tiene en marcha el Proyecto "NIDO" dirigido a gitanos rumanos "menores en riesgo social y sus familias" en edades comprendidas entre 8 y 18 años. El "grupo diana" son estos menores que presentan un alto índice de absentismo escolar y que a veces han cometido actos delictivos, en su mayoría pequeños robos, y presentan una tendencia a la mendicidad, sobre todo femenina.

Coordinación y trabajo conjunto con centros de protección de menores, centros de internamiento, Equipo sanitario de Intervención con Población Excluida (EIPE), educadores sociales de los servicios sociales del distrito, colegios e institutos de la zona.

Intervención familiar en un proceso de transformación de la comunidad aceptado por sus miembros y orientado a rescatar todos aquellos aspectos que desarrollen potencialmente $y$ les hagan integrarse en nuestra sociedad.

Actuación con los menores centrada en la realización de un seguimiento educativo individual y en actividades de animación sociocultural.

Se propone trabajar con los niños y adolescentes de estas edades en la formación prelaboral. El dispositivo que parece más idóneo para las necesidades del Gallinero es el de "Es-
cuela-Taller". En él el alumno a la vez que aprende de una forma teórico práctica, va "construyendo" algo, va viendo el fruto de su trabajo que se objetiva en la obra trabajada y en la remuneración económica que recibe. Su concreción figura el Plan Alternativo a la desalojo de El Gallinero que ha emprendido la administración.

Proyecto "MALALA"

Específico del proyecto "NIDO" para niñas adolescentes. Pretende romper el ciclo de pobreza de las mujeres de El Gallinero empoderando a las adolescentes para convertirlas en agentes de la transformación social. Naciones Unidas recuerda que la educación es una de las mejores estrategias para proteger a las niñas de los matrimonios infantiles y para proveerles de las oportunidades que necesitan para construir una vida mejor. Que sean capaces de no repetir el caminos de sus madres (desarrollo de habilidades laborales versus pedir) y así se casen cuando quieran, con quien quieran y tengan los hijos que quieran.

Empoderar a las Niñas. "El desarrollo de los pueblos o viene de las mujeres o no viene". Que las niñas no se sientan condenadas a pedir. Que no dejen la escuela a los 10 años, cuiden los hijos de sus madres hasta que se casen a los 14 y empiecen a pedir a los 15 para alimentar al primer hijo. 


\section{expovida}

\section{EXPOVIDA EN LOS BORDES}

Educar a otros en los derechos humanos desde la admiración de la bondad y la belleza.

Una exposición de cincuenta fotografías, hechas en El Gallinero por grandes fotógrafos comprometidos, nacionales e internacionales. Con la fuerza y la honestidad de su mirada muestran que hasta en los bordes inhabitables de las grandes urbes, allí donde van los desechos urbanos, se produce un resultado paradójico: una fuerza vital a prueba de infortunios y la confianza en salir adelante. Hay vida. Una vida que gracias a ellos deja de ser invisible. Esta exposición lleva más de un año recorriendo parroquias, centros culturales, universidades, institutos, colegios... Escríbenos si te interesa.

\section{Y TODO ESTO... ¿POR QUÉ?}

Aunque después de 10 años, si me preguntan por qué hago esto de educar a unos niños rom, respondo que "porque los quiero", no está de más añadir eso que se llaman motivos "superiores", si es que hay algo superior al amor. Así puedo añadir:

I. "Las obras de misericordia no han caducado" (Is 58, 7 y Mt 25,35). En esto parece que el papa Francisco está de acuerdo conmigo. En enseñar al que no sabe, me encuentro con el reto peliagudo de enseñar al que no quiere. Eso es lo que dicen los que piensan que no merece la pena insistir; que los rom no se merecen esta inversión. Pero, ipor qué no quiere? Hay que preguntárselo sin tirar la toalla. Es evidente, porque no sabe. Trabajar incansablemente para que sepan es el único modo de salir de este círculo vicioso. Hay que concederles mucho tiempo para aprender. El mismo que tardamos nosotros, y nosotros empezamos la escuela con nuestros retatarabuelo... Queremos que dejen de ser analfabetos ya; hay que ir despacio. El que un adulto de 40 años que parece que tiene 60 , venga a la escuela y empiece a dibujar las letras..., es algo que hace por primera vez en la vida y dentro de muchas generaciones. Es un gran comienzo el que empiece a necesitar otra forma de comunicarse. Igual no vuelve en 15 días..., no importa, el veneno ya está dentro.

2. Es mi deber devolver la educación que recibí. Es un imperativo moral trabajar por la erradicación de la pobreza. Es mi deber intervenir desde el enfoque de los Derechos Humanos. Ello implica:

- Partir de lo que tienen y no desde lo que carecen. Y lo que más tienen es dignidad y derechos de los que han sido despojados desde que nacieron

- Situar a los habitantes de El Gallinero como ciudadanos, centro de la intervención y protagonistas de sus procesos de inserción social; así buscamos que sean capaces de tomar decisiones sobre las alternativas de su presente y agentes de la reivindicación y defensa de sus derechos a los que tienen que dotar de contenido.

- Poner continuamente en relación directa sus necesidades básicas no cubiertas (educación, sanidad, vivienda, juego...) con la posible vulneración o incumplimiento de un derecho humano reconocido Declaraciones y Conferencias ONU, Pactos y convenciones. Exigimos a la Comunidad y al Ayuntamiento de Madrid que se respete la legislación internacional sobre los desalojos de los asentamientos precarios y un escrupuloso respeto a la dignidad humana básica.

3. Enseñar contra toda esperanza. Trabajamos proféticamente. Tenemos delante los sociológicos pronósticos que auguran la necesidad de que pasen dos o tres generaciones para lograr satisfactorias integraciones sociales de la población migrante. Ello me lleva a no renunciar a dejar pasar, sin actuar, esta generación de los niños de hoy. No sé si mañana se integrarán ellos o sus hijos, pero sí estoy seguro de que ellos, y gracias al esfuerzo de los que conmigo trabajan, hoy no se distinguen
Son las 8 de la mañana. Hora de ir al colegio. Pero hoy, Alin Paun, nueve años, el mayor de cinco hermanos que asiste en el Colegio Blas de Otero a un aula de enlace, no quiere ir la escuela. Está mirando, tras el visillo de su chabola en El Gallinero cómo la excavadora del Ayuntamiento de Madrid destruye la chabola de enfrente.

$Y$ no quiere que le pase como a otros niños que, días atrás, al volver del colegio, se encontraron que ya no tenían dónde vivir.

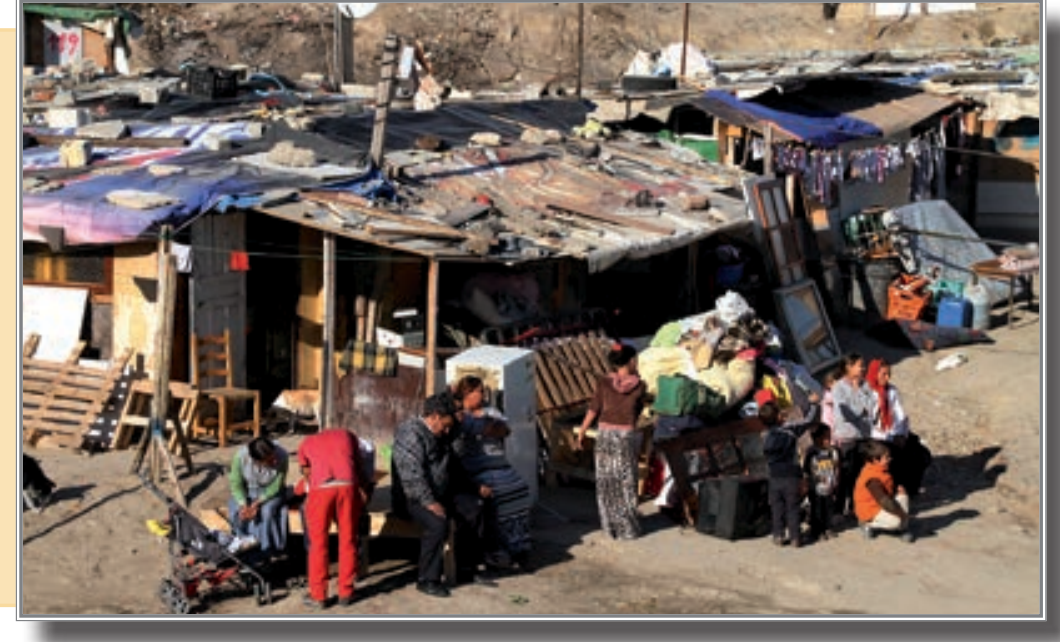

Foto:Javier Baeza 
ANUNCIAMOS UNA bUENA NOTICIA (PROPUESTA UTÓPICA): TENEMOS UN PLAN

Una nueva tierra, un nuevo barrio, fruto de la educación, integrado en el entorno.

- Las parroquias que trabajan en El Gallinero han desarrollado, con la ayuda de la Escuela de Arquitectura de la Universidad de Alcalá de Henares y otros voluntarios de diferentes disciplinas, un proyecto que prevé trasladar a los habitantes del Gallinero a un lugar integrado en el tejido urbano y en la sociedad, que reúna condiciones básicas de habitabilidad y acceso a los servicios públicos.

- Los impulsores del plan solicitan un terreno de 40.000 metros cuadrados al Ayuntamiento (actualmente ocupan 20.000) en los que construir con materiales sencillos casas "semilla" y de $45 \mathrm{~m}^{2}$ (dos habitaciones, salón, cocina y baño) que puedan ampliarse a medida que crezca la familia.

- El sistema que proponen los impulsores del proyecto es una "autoconstrucción dirigida", formando a los habitantes a través de escuelas taller para que ellos mismos puedan ir levantando sus casas y espacios comunes $y$, a la vez, adquiriendo una profesión que les aleje de la mendicidad, y de las ayuda sociales.

- El coste del plan (materiales + personal técnico + becas formación) alcanzaría los dos millones y medio de euros que provendrían del Programa Europeo para la Integración de la Comunidad ROM europea y del Programa Estatal de Inclusión Social. Los recursos que actualmente dedican Ayuntamiento y Comunidad al Gallinero, para una atención social provisional, bastarían para cubrir la cuarta parte de ese plan definitivo.

de otros niños de Madrid cuando juegan al futbol, van al teatro, pasean con sus monitores por la calle de Alcalá, o reciben a los Reyes Magos.

En este trabajo hemos tenido que denunciar la inhumana y escondida política municipal del "que se vayan, que se marchen", y para ello el acoso y derribo que supone a los derechos humanos la continua práctica del desalojo. No importa destrozar con la excavadora varias chabolas, que para ellos no deja de ser su domicilio, su casa (y "Toda persona tiene derecho al respeto de su vida privada y familiar, de su domicilio...", Artículo 7 de la Carta de los Derechos Fundamentales de la Unión Europea), donde vive una familia con 5 o más hijos (y "por aquello de la misa de la Sagrada Familia en Colón, la familia es sagrada, y su desalojo una especie de "sacrilegio") con 7 y 8 hijos. Y para más inri, se efectúan los derribos justo a la misma hora en que los niños van al colegio. Ellos iban, y las máquinas y la policía que venían a tirar sus casas, venían. Qué niño va a querer ir a la escuela ese día sabiendo que al volver puede que no tenga casa... El niño que ha tenido que ir a mal dormir muchas noches a otras chabolas hasta poder levantar la suya itendrá

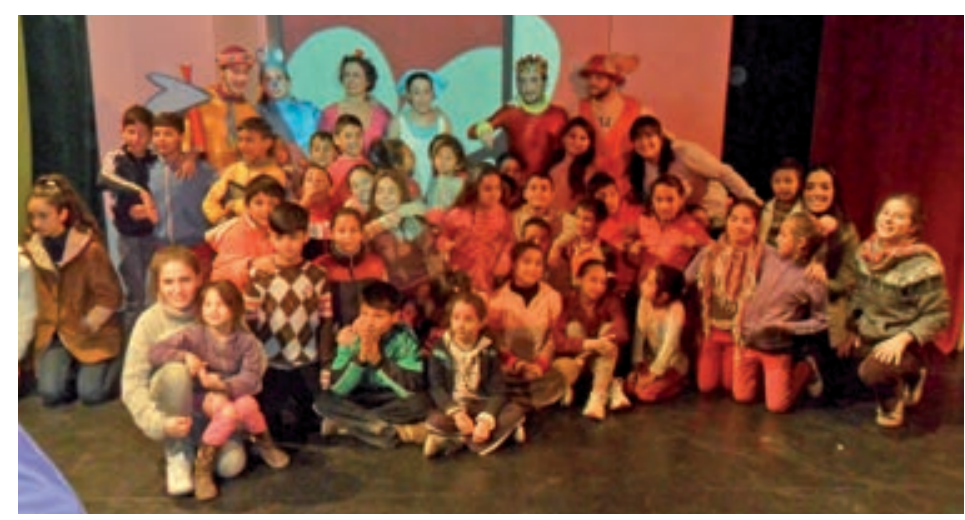

Niños de El Gallinero (de 6 a 12 años) se retratan con los actores de Réplica Teatro que representaron Alicia, basado en Alicia en el país de las maravillas; los monitores que les acompañan son alumnos y exalumnos de bachillerato del colegio Jesús María del barrio de San Blas (buscar en Facebook: Proyecto Veo Veo). fuerzas para levantarse y coger la ruta? ¿Cómo entender que el mismo trabajador social municipal que me manda ir a la escuela es el mismo que veo al lado del que me machaca la chabola, sus tablas, su techo, los pobres enseres..., para que no pueda levantar otra, y deja a mi familia sin nada de lo que tanto tiempo les costó recoger y que no les deja vivir dignamente?

Un argumento "educativo" para que se queden en la zona de Vallecas, la de sus colegios y no les desplacen a los campamentos del norte de Madrid.

Como en el drama de Shakespeare, El mercader de Venencia, Shylock, el Ayuntamiento, puede cobrarse la libra de carne, es decir derribar chabolas por infracción urbanística pero no puede, ni tiene derecho, a derramar ni una sola gota de sangre: destrozar el trabajo educativo que durante años han venido desarrollando con los niños los maestros de la zona (isabes que cuando se enteran que uno de sus alumnos se vuelve a Rumanía, algunos lloran?) y los voluntarios "forzosos", violando su derecho a la educación, un derecho humano prioritario y retrasando, por lo menos en una generación, la integración social de la población roma.

Claro, esto se explica porque para la Concejalía de Familia y Asuntos Sociales del Ayuntamiento de Madrid, "los DDHH son una cosa del tercer mundo" [sic]. Me alegro de pertenecer al tercer mundo y no al cuarto, en el que el Director General que lo dijo se cree que está (ni dimite ni se le espera, sigue en activo y mandando). Me abochornaría estar en el mismo mundo.

\section{hemos hablado de:}

\section{Inmigración; voluntarios; escolarización infantil;} educación integral.

Este artículo fue solicitado por PADRES Y MAESTROS en julio de 2013, revisado y aceptado en febrero de 2104 para su publicación. 